\title{
Analysing Gender and Institutional Change in Academia: Evaluating the Utility of Feminist Institutionalist Approaches
}

\author{
Sara Clavero \\ Technological University Dublin \\ Yvonne Galligan \\ Technological University Dublin, yvonne.galligan@tudublin.ie
}

Follow this and additional works at: https://arrow.tudublin.ie/aaschsslarts

Part of the Sociology Commons

\section{Recommended Citation}

Clavero, S. \& Galligan, Y. (2020) Analysing Gender and Institutional Change in Academia: Evaluating the Utility of Feminist Institutionalist Approaches, Journal of Higher Education Policy and Management, 42(3):1-17 DOI:10.1080/1360080X.2020.1733736

This Article is brought to you for free and open access by the Social Sciences at ARROW@TU Dublin. It has been accepted for inclusion in Articles by an authorized administrator of ARROW@TU Dublin. For more information, please contact arrow.admin@tudublin.ie, aisling.coyne@tudublin.ie,gerard.connolly@tudublin.ie.

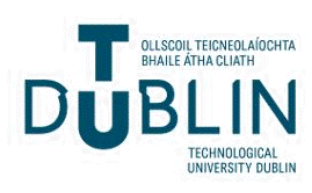




\title{
Analysing gender and institutional change in academia: evaluating the utility of feminist institutionalist approaches
}

\author{
Sara Clavero and Yvonne Galligan \\ Technological University Dublin
}

\begin{abstract}
This article explores research on gender and institutions for the purposes of informing analytical frameworks for research on institutional change with regard to gender equality in higher education. Drawing on feminist institutionalist studies that explore the relationship between gender, institutions and institutional continuity and change, the aim is to evaluate how this body of scholarship can be adapted to an analysis of the dynamics of gender equality plan implementation in universities.
\end{abstract}

Key words: Higher education, institutions, institutional change, resistance, informal rules, gender equality.

\section{Introduction}

Over the past decade, the study of gender and institutions has developed into a prolific research agenda, with distinctive sets of concepts, theoretical frameworks, objectives and tools. Led mainly by feminist political scientists, gender and institutions research seeks to understand the role of institutions in the reproduction of gender-power relations; the gendered dimensions of institutional continuity and change; and the factors leading to success or failure of feminist strategies such as gender mainstreaming, gender quotas and other gender policies (Mackay, Kenny and Chappell 2010, Krook and Mackay 2011).

Drawing on feminist institutionalist theory, this article aims to inform studies exploring the interactions between gender and institutional change in universities. It also seeks to understand the role of resistances to institutional change that accompanies the implementation of gender equality plans (GEPs). How such resistances can be identified, measured and ultimately overcome represents a major challenge for both scholars and practitioners in the field of gender equality in higher education today.

Academic explorations of the relationship between gender, institutions, and institutional continuity and change have been making important strides since the late 1980s, and especially after the publication of Joan Acker's influential work on gendering processes in organisations (Acker 1990, 1992). Building on previous feminist contributions to the field (Kanter 1977, Martin 1985, Smith 1987), in Acker's account, to say that an institution is 'gendered' means that gender is present in its processes, practices, images, ideologies, and distributions of power (1992: 567). In their view, the creation and recreation of the gender structure embedded in organisations requires an investigation into institutional practices.

Acker's theory of gendered organisations explains persistent gender inequality in organisations but is limited in explaining institutional change. Gender scholars seeking to better understand institutional continuity and change in relation to gender equality have turned to new institutionalist theory developed in political science. A central tenet of this theory is that 
change is mainly driven by the internal dynamics of institutions rather than by broader societal forces or by the properties of individual actors. Therefore, any analysis of institutional change requires knowledge about the specific institutions under study, including:

the internal success criteria, structures, procedures, rules, practices, career structures, socialization patterns, styles of thought and interpretive traditions, and resources of the entity (Olsen 2009: 9).

Feminist institutionalist scholars draw on the potential of new institutionalism for improving our understanding of the gender dynamics at play in institutional design, institutional practices and institutional change. Critiquing the gender blindness of 'mainstream' institutionalist theories, these scholars argue that the application of a gender lens could provide fresh insights into the field (Chappell 2006, 2011; Chappell \& Waylen 2013; Kenny, 2007; Krook \& Mackay 2011; Mackay \& Waylen, 2009; Mackay, Monro \& Waylen 2009; Mackay, Kenny \& Chappell 2010).

Higher education institutions have their own set of distinctive features when compared to those most extensively studied by institutionalist scholars-i.e., government bureaucracies and parliaments, political parties and electoral systems. Therefore, a study of gender and institutional change in universities informed by a feminist institutionalist approach requires careful attention to the features described by Olsen and applied to the higher education context. Consideration must also be given to the significant variations among and within universities. As Van den Brink and Benschop note, universities are not monolithic institutions, as different academic fields 'vary in their core activities, financial resources, career patterns, epistemological issues and publishing strategies' (2012: 72). Furthermore, variation between universities, both among and within countries also needs to be taken into account especially when comparing institutional change patterns (authors 2017).

To date there is little research informed by feminist institutionalist perspectives that examines institutional continuity and change in higher education contexts. At the same time, there is a growing body of literature which, informed by gender and organisational theory, explores the gendered nature of universities (Kezar and Eckel 2002; Erickson 2012; Benschop \& Doorewaard 2012; Lester 2008; Lester, Sallee and Hart 2017). While this research is not specifically informed by a new institutionalist framework, it is making valuable contributions to our understanding of gender in higher education.

The article is divided in four sections. The first section sets out the contextual background, providing an overview of efforts to implement gender equality policies in higher education institutions in Europe and the impact so far in achieving goals. Section two provides a review of the literature on gender and institutions, while section three turns to the question of how this knowledge has been applied in research examining resistances to institutional change towards gender equality, with a special focus on higher education institutions. Finally, section four explores how feminist institutionalist approaches can inform a study of gender, institutions and institutional change in universities.

\section{Contextual background}

In European universities, policy action towards gender equality, typically in the form of gender equality plans (GEPs), is becoming widespread. As one might expect, there is variation in relation to national coverage as well as the time when these initiatives were first introduced in each country. For example, German universities began to develop GEPs as far back as the 1980s; universities in Austria and Sweden in the mid-1990s; those in the United Kingdom in the late 1990s; in Italy and Spain in the mid-2000s; in France and Ireland in the mid- 2010s; 
while in other European countries, GEPs in universities are only beginning to emerge (European Commission 2019a).

At European Union (EU) level, the 2015 Council conclusions on advancing gender equality in the European research area invited EU Member States and research funding organisations to provide incentives to encourage higher education institutions and research organisations to develop gender equality plans (GEPs) and to mobilise adequate resources to implement these plans (Council of the European Union, 2015). The EU has actively promoted these actions, mainly through its research and innovation programmes (FP6, FP7, Horizon 2020) and other supportive instruments, such as the European Institute for Gender Equality's GEAR online tool designed to inform and guide universities in setting up and implementing GEPs (EIGE 2016). There are also transnational initiatives in place, such as the commitment of the League of European Research Universities (LERU) to develop and implement GEPs in all its member institutions (LERU 2012).

Data on progress in gender equality in higher education institutions suggest that those policy and legislative efforts have had some impact. For example, in the EU the proportion of women at senior levels in the academic hierarchy rose from 15\% in 2004 (EU-25) to 22\% in 2013 (EU28 ), and to $24 \%$ in 2016 . However, data continue to portray a sector in which significant gender inequalities persist. These concern the gender distribution of staff at different stages of their academic/research careers (vertical segregation) and across different disciplines (horizontal segregation), as well as in university governance structures. In 2013, women made up only 22 $\%$ of grade A staff (full professorial level) in the EU, and this gap was even more pronounced in the field of science and engineering, where women represented only $13 \%$ of academics at this grade (European Commission, 2016:126; 2019b:115). Gender gaps also persist in governance bodies: in 2014 the proportion of women among heads of higher education institutions in the EU-28 was a mere $20 \%$, which increased modestly to $22 \%$ in 2017 (European Commission 2019: 129).

If these figures are contrasted with similar data in other sectors, it becomes clear that progress towards gender equality in higher education institutions is less advanced than it is in other sectors. For instance, in 2017 women made up $25 \%$ of public company board members, $28 \%$ of senior ministers and 29\% of Members of Parliament (European Commission 2018: 65).

Quantitative data, however, only reveal the tip of an iceberg and are symptomatic of endemic gender inequality practices in academic institutions. Furthermore, experiences in gender equality initiatives elsewhere have shown that even if women reach parity with men in different structures of the academy, there is no guarantee that those institutions will operate in a more egalitarian manner (Penney, Brown and Oliveria 2007). As Van den Brink and Benschop (2012: 71) observe 'gender inequality resembles an unbeatable seven-headed dragon that has a multitude of faces in academic life'.

In understanding why policy efforts towards gender equality are not being translated into desired outcomes or why the pace of progress in this regard is slow and uneven, the literature on gender and institutions, particularly its feminist institutionalist variants, can provide an illuminating analytical framework.

\section{Gender and institutions}

Feminist scholars have been interested in gender and institutions since Kanter's (1977) pioneering work on gender and the dynamics of organisational behaviour. The focus of that research was not on the inherently gendered nature of institutional structures, but rather on the numerical composition of management teams. However, their work had an important influence 
on research into gender parity in a variety of institutions, as they considered how maledominated decision-making groups react when women join in varying proportions.

Joan Acker was the first scholar to fully theorise the institutional embeddedness of gender. Acker coined and defined the term 'gendered institutions' to mean that gender 'is present in the processes, practices, images, ideologies, and distributions of power in the various sectors of social life' (1992: 567). While the norms of values of organisations are presented as 'gender neutral' (i.e., wrapped in a veil of objectivity and assuming a disembodied and universal worker) they are de facto deeply androcentric. Acker (1990) identified the multiple ways in which gender inequalities manifest in organisations. First, it is manifest in a division of labour where men are almost always in greater numbers in the highest positions of organizational power (e.g. higher faculty ranks in universities and in management and governance structures). Second, gendered organisations have symbols, language, and images that reinforce those unequal labour divisions (e.g., image of a professor as a successful white man endowed with epistemic authority). Third, gender inequalities in gendered organisations are manifest in interactions of dominance and submission between actors (e.g., women being interrupted more often than men in a faculty meeting). Fourth, in gendered organisations, actors take on gendered ways of thinking about work (e.g., that to have a successful academic career, it is necessary to work all hours). Fifth, gendering is embedded in organizational logic in a way that, for example, systems of job evaluation favour male characteristics and preferences for work roles (e.g., evaluative criteria in academia that favour careers with no interruptions, research over teaching and pastoral work, and international mobility).

However, Acker's theory has been criticised for its limitations in explaining how institutional change can occur. If individuals in a gendered organisation operate through gendered identities that are shaped by organisational norms, individual agency to change gendered organisations is suspended. It may be far more difficult to individually change and challenge the gendered system than to replicate existing norms and structures, yet evidence exists that some individuals, and more particularly groups, can alter organisational structures and cultures through acts of agency (Meyerson 2003; Kezar and Lester 2011). For example, Hart's research (2008) found that feminist faculty groups were successful at improving the climate for women in their campuses. It showed that the degree to which women in these movements felt constrained by the organization and their profession was not universal and that change was possible through the promotion of more equitable practices over time.

Connell's work on 'gender regimes' has also provided an important contribution to the thinking on gender and institutions. Institutions, according to them, can be seen as 'gender regimes' a patterning of four sets of gender relations that includes: the gender relations of power; the gender division of labour; the gender dimension of emotion and human relations; and the gender dimension of culture and symbolism (Connell 2002). Acknowledging the existence of a gender regime is important because it provides new insights into how power relations in institutions produce and contest gender inequalities.

Feminist political scholars have made significant contributions to these questions, as they have been long interested in the factors conducive to institutional change through institutions, movements and policies such as women's policy agencies, positive action interventions and gender mainstreaming. This research has analysed in detail the interaction between women's movements and political institutions within the context of political opportunity structures, with the aim to understand the factors facilitating and constraining change towards gender equality (Outshoorn and Kantola 2007, Lovenduski 2008, McBride and Mazur 2010). However, in understanding the varying degrees of success of those initiatives, this research has come up against important limitations. One such limitation is a narrow focus on gender-specific 
institutions, which makes it difficult to uncover the internal gender dynamics of institutions and institutional change more generally (such as institutions of higher education). A second limitation is a tendency to overemphasise women's agency without paying sufficient attention to structural constraints in achieving institutional change (Waylen 2014: 215)

Against this backdrop, gender and politics scholars sought to improve the analytical frameworks for understanding institutional continuity and change in relation to gender equality and the gap between formal rhetoric and the practice of gender policy initiatives. Feminist institutionalism developed in the early 2000 s in response to the scholarship of new institutionalism, which was rediscovering and theorising on the inter- and intra- dynamics of political institutions (Mackay, Kenny and Chappell 2010).

For feminist institutionalists, to say that an institution is gendered means that constructions of masculinity and femininity are intertwined in its daily life and logic rather than existing independently of the institution (Kenney, 1996: 456). Feminist institutionalism also brings power to the forefront of institutional analyses. While issues of gender and power have long been a central concern of feminist scholarship in general, it is only recently that feminist political scientists have turned to the importance of institutions in both reflecting and reinforcing gender-power relations (Mackay, Kenny and Chappell 2010: 578).

A major point of commonality between feminist approaches to institutionalism and new institutionalist analysis is a focus on both formal and informal institutional rules. The distinction between formal and informal rules can be useful for understanding why the introduction of new formal rules (e.g., gender parity in evaluation panels) is not always translated into intended actions and desired outcomes, since informal rules - which often take subtle forms, such as patronising, shunning or social ostracism - can play an important role in undermining institutional change (Chappell and Waylen 2013, Waylen 2014). Thus, a change in the formal rules of an organisation may end officially sanctioned gender inequalities without ending gender inequality in all its forms.

Feminist institutionalism also emphasises the importance of strategic agency in institutional change, highlighting the ways in which actors initiate change within a context of opportunities and constraints (Chappell 2002, 2006). Resistance to change appears when individuals internalise the existing informal gender norms of an organisation. As Acker observed "a belief that there is no point in challenging the fundamental gender, race, and class nature of things is a form of control. These are internalized, often invisible controls" $(2016,454)$. Yet research on gender and organisations has shown how actors can change the norms and institutional structures in which they operate (Fox 2008; Kezar 2014; O'Meara and Stromquist 2015; Ward and Wolf-Wendel, 2012). Institutions, in sum, are not only gendered but they can be degendered as actors make changes to the status quo.

According to feminist institutionalists, change is made possible because institutions are full of contradictions and conflicting interests and, therefore, can create opportunities for the exercise of feminist agency (Kantola 2006). Nonetheless, the institutional context in which actors operate can constrain or facilitate actions in important ways. Understanding this context involves paying close attention to the gender dimensions of both the formal and informal rules that exist in an organisation.

The task of identifying informal rules and evaluating their role in facilitating and constraining institutional change towards gender equality poses methodological challenges. This is because informal rules are hidden. They are embedded in everyday gendered practices that are disguised as standard behaviour and are, therefore, taken for granted. Overcoming this challenge requires carefully designed research methodologies (Chappell and Waylen 2013). How feminist 
institutionalist theory - in its different variants - can be used as a framework for an analysis of institutional continuity and change in specific academic contexts is a question to which we will return in section 4.

\section{Resistance to gender equality in higher education: the role of merit}

An increasing number of universities across Europe are developing gender equality action plans (GEPs). While their adoption can be unproblematic, their impact on institutional change depends on a variety of factors such as knowledge and awareness of gender issues through gender theory and research evidence, commitment from senior management, sufficient levels of human and financial resources, leadership at all levels, and sustained stakeholder engagement (EIGE 2016, see also, Thomas et al. 2017).

Traditionally, the focus of research on institutional change has been on understanding success, although cases of unsuccessful implementation of gender equality initiatives are common. Erikson-Zetterquist and Renemark (2016) make a distinction between formal and informal elements of institutional change. Gender equality principles may be easily introduced into the formal structures of an organisation, yet for these formal elements to make an impact on the day-to-day routines, they need to be translated into stabilised practices, otherwise gender equality goals can easily fade away.

In analysing cases of implementation failure, authors are using the concept of resistance as an organising principle of research with a powerful explanatory potential. Mergaert and Lombardo $(2013,2014)$ unpacked the concept of resistance to institutional change in a study examining failure in the implementation of gender mainstreaming in EU research policy. As a typical case of unproblematic policy adoption but of little tangible progress resulting from policy implementation, their analysis focused on the concept of 'resistance' as a primary factor explaining lack of success. They defined resistance as:

a phenomenon that emerges during processes of change — such as when gender equality policies are implemented - and that is aimed at maintaining the status quo and opposing change (2013: 299).

Resistance is a largely invisible phenomenon which only becomes manifest during processes of change. For analytical purposes, these authors make a distinction between two main types of resistances - institutional and individual- both of which can be expressed either explicitly or implicitly. Institutional resistance, in their definition, is 'revealed by a pattern of aggregated action or inaction that is systematically repeated and that suggests a collective orchestration against gender change' (Mergaert and Lombardo 2014, 9), while individual types of resistance are exercised by individual actors and manifested in action or inaction opposing change.

Resistance to change towards gender equality is of special interest to scholars analysing implementation failure from a feminist institutionalist perspective. Yet, its analysis presents a number of challenges. The first one is how to select case-studies of implementation failure. Bergqvist, Bjarnegård and Zetterberg (2013) draw a distinction between two forms of nondecision-making - 'failure' and 'status-quo' - and contend that for 'failure' to happen the 'status-quo' must be challenged in one way or another. It is only in such cases that resistances can emerge and, therefore, be identified.

Once the case-studies of implementation failure have been selected, a second challenge is how to identify instances of resistance. If the concept is not adequately defined and operationalised, resistance can be either misidentified or misrecognised. An added difficulty is that both institutional and individual types of resistance can be expressed implicitly. Explicit manifestations of institutional resistance will be easier to detect as these 'can take the form of 
policy discourse that expresses ideas and aims that distance themselves from the goal of promoting gender equality, or it can take the form of actual policy actions that go against that goal' (Lombardo and Mergaert 2013: 301). By contrast, implicit resistance does not manifest overtly and it can find an expression in lack of action (Mergaert and Lombardo 2014: 8). This renders its identification rather problematic as not all instances of inaction can be interpreted as expressions of implicit resistance. Identifying this type of resistance thus requires an empirical analysis of data collected through qualitative methods such as participant observation, semi-structured interviews and/or focus groups. The main focus of these datagathering exercises will be on actors and the strategies used to resist change. These actors may work either collectively or individually, but they may also work across institutional boundaries so that so that it may be necessary to look beyond the organisation to understand the dynamics of resistance in the implementation of a GEP (Annesley and Gains, 2010).

Once resistances have been identified, new institutionalist theory posits that they should be traceable to institutional rules, whether these are formal or informal. However, not all identified resistances may traceable to institutional rules that are specifically about gender. Gains and Lowndes (2014: 528) contend that, in studies of gender and institutional change, the focus should rather be on rules that have gendered effects. Examples include informal rules about what makes a good leader, about timing and location of meetings, or about the appropriate age for specific roles within the organisation. Similarly, in a study of faculty women in Science, Technology, Engineering and Mathematics (STEM), Hart (2016) uncovered a variety of informal institutional rules and practices around access to networks, assignment of workloads, promotion processes and pathways to leadership, all of which have powerful gender effects as they have been shown to disadvantage women academics.

Experiences in GEP implementation have detected a variety of resistances, yet systematic analyses are rare. Using qualitative content analysis of interviews as their main methodology, Van den Brink and Benschop (2012) conducted an empirical study of the obstacles in the implementation of gender equality initiatives in the recruitment and selection of full professors in seven Dutch universities. The objective of their study was to reach a better understanding of the limited effect of gender equality practices in achieving sustained institutional change in academic institutions. Their study found a myriad of gender inequality practices that hinder, obstruct, and even hijack, practices aimed at a more balanced representation of women and men in professorial posts. These include, amongst others, opaque selection and promotion criteria and procedures; persistence of patriarchal support networks; a paternalistic view that combining a career with family responsibilities is too hard for women, and gender stereotypes shaping the image of the 'ideal scientist'.

However, one particularly salient resistance to gender equality initiatives found in all the fields analysed in their study was a pervasive attachment to the principle dictating that candidates should be appointed on the basis of their merit. This is a principle that is inherently gender biased, although it is based on the assumption that the academic recruitment system is gender neutral, offering equal opportunities to all candidates irrespective of their gender, insofar as they are equally meritorious (see also Heward 1994; Bagilhole and Goode 2001; Scully 2002; Krefting 2003; Morley and Lugg 2009; Thornton 2013; Trevino et. al 2015). The authors conclude that the deep institutional entrenchment of merit renders invisible the discrepancy between academic values and actual practices and outcomes. As a result, institutional rules go unquestioned as standards for promotion and appointments are viewed as fair, offering the same opportunities to all candidates. Furthermore, as institutional rules in recruitment and selection are perceived to be beyond reproach, gender inequality is regarded as a problem of 'supply'; in other words, women lack the profile, record or experience required to be meritorious candidates and successful applicants. 
To sum up, the study revealed the role of 'merit' as a core institutional principle that is at the root of much resistance to change, not just in policy implementation but as early as policy formulation, as their approach identified resistances at the very early stages of the policy process. If it is assumed that the 'merit' principle governs not only the processes of selection, recruitment and promotion of academic staff, but other academic activities as well (e.g., publication and dissemination activities, research grant allocations, and so on) then this concept must be deconstructed and its role in gender practices in academic institutions unveiled. As one feminist scholar puts it, this is a concept that 'lies at the heart of the intractable gender binary within the academy' (Thornton 2013: 128).

The task is not without challenges, as merit is a concept that goes unquestioned while it shapes the way we interpret reality. This means that any evidence of gender gaps in relation to percentage of professors, research project leaders, or publications, is not seen as a problem with merit but rather as one of gender barriers that keep women from reaching the standard of excellence required, such as, for example, difficulties in balancing work and family life, or lack of confidence (Ward and Wolf-Wendel 2012).

Measures to tackle gender bias when assessing academic merit in recruitment and promotion processes are now included in a large number of GEPs of European universities. Two typical types of measures are gender parity in selection committees and compulsory gender bias training for committee members. In addition to this, a variety of initiatives aimed at changing how excellence is measured have been set in place with a view to tackling not only gender biases in assessments of merit but also to change the criteria by which those assessments are made, addressing its gendered assumptions. One such initiative is the Code of Conduct for the Recruitment of Researchers, adopted by the European Commission in 2005. The Code consists of a set of general principles and requirements that should be followed by employers and/or funders when appointing or recruiting researchers, providing a common policy framework in the European Research Area (ERA). The Code contains a number of non-legally binding principles that are relevant to gender equality. It recommends that selection committees should have an adequate gender balance and that recruitment and selection processes should be open and transparent. It also recommends that evaluations of merit should focus on 'results within a diversified career path and not only on the number of publications'; that bibliometric measures 'should be properly balanced within a wider range of evaluation criteria, such as teaching, supervision, teamwork, knowledge transfer, management of research and innovation and public awareness activities', and that career breaks or variations in the chronological order of CVs should not be penalised but regarded as an 'evolution of a career' (European Commission 2005: 25-26). The Code incorporated many recommendations of a previous European Commission report on "minimising gender bias in the definition and measurement of scientific excellence" (European Commission 2004). These recommendations covered five areas where gender bias was identified: a) the characterisation of scientific excellence; b) the criteria used to assess it; c) the choice of the explicit and implicit indicators for scientific excellence;(c) the way the criteria are applied to men and women; d) the failure to integrate women in scientific networks; and e) the procedures through which criteria are applied to people.

However, the impact of these initiatives on GEP design and implementation is still intangible. A recent analysis of GEP actions to redress gender inequalities in the hiring and promotion of academic staff included in the GEPs of six European universities (authors 2018) found that only two universities (Barcelona and Science Po) had measures in place to tackle gender discrimination in the criteria used in assessments of merit. Furthermore, the wording of these measures was vague, providing next to no detail. In the GEP of Science Po this was included in a more general action to implement the European Code of Practice for the Recruitment of 
Researchers. The GEP of Barcelona guaranteed that the criteria used in the evaluation of CVs did not contain any element of indirect discrimination, yet it failed to explain how this guarantee was to be implemented.

Given the invisibility of the gendered construction of academic merit, uncovering its role in perpetuating gender inequalities and hindering institutional change in higher education settings requires carefully designed analytical frameworks and methodological approaches.

\section{Researching gender and institutional change in academia. A feminist institutionalist framework.}

In researching the origins, continuity and change of gendered institutions, feminist institutionalists have developed their own analytical frameworks by drawing on different variants of new institutionalism: rational choice (RCI), historical (HI), sociological (SI) and discursive (DI). While each of them have been used for understanding different aspects of the relationship between gender and institutions, the choice of approaches largely depends on the type of institutions under study and the specific questions, objectives and focus of the research.

Rational choice institutionalists (RCI) focus on the role of institutional rules in constraining actors' behaviour. In their view, actors' behaviour is driven by a strategic calculus that is aimed at maximising their own interests, although this calculus will be affected by expectations about how others are likely to behave. Institutional rules structure these interactions by restricting actors' choices but also by eliminating uncertainty (Hall and Taylor 1996). Rational choice and feminist institutionalists exist in an uneasy relationship to one another. Feminists consider rational choice theory to be based on assumptions about the gendered world that are both sexist and androcentric, while rational choice scholars ignore the intellectual contribution of feminist scholarship to understanding motivation, interests and behaviour (Driscoll and Krook 2009, 238-239). Nonetheless, their very different starting points can create a strong analytical perspective when combined, as Driscoll and Krook (2009) illustrate in relation to explaining the adoption of gender quotas in politics. There are increasing examples of various forms of preferential action, up to and including quotas, being put into effect in higher education. One example is the creation of full professorial and other academic posts to which women's applications are given preferential treatment. Instances include the Senior Academic Leadership Initiative (SAL Initiative) of the Irish government, the University of Delft (Netherlands) scheme for women-only fellowships and the University of Melbourne, Australia female-only posts in the School of Mathematics and Statistics. Each of these initiatives is designed to address the lack of female representation in disciplines and seniority in higher education. A feminist institutionalist rational choice approach could illuminate why male academic elites approve of measures that on the face of it affect their self-interests. However, to date, there has been very little appetite among feminist scholars to expand on what a feminist RCI approach would look like, and to apply it in any field, including higher education studies.

Sociological institutionalists (SI) emphasise the social rather than the structural features of institutions. In their view, institutions are 'systems of meaning' that reflect shared understandings of the way the world works. Thus, institutions do not only include rules and practices, but are also 'symbol systems, cognitive scripts and moral templates that provide the frames of meaning guiding human behaviour' (Hall and Taylor, 1996: 947). Institutional actors are, in sum, social beings who act in habitual ways, following a 'logic of appropriateness' that both prescribes and proscribes certain types of behaviour (March and Olsen 1989).

Feminist revisions of SI, particularly in the attention given to culture, can counterbalance a rational-choice conception of institutional actors and illuminate the role of informal rules in resisting gender equality in academic settings. For SI scholars, institutional practices are not 
rooted in rationality but rather in a 'logic of appropriateness' based on norms which are widely valued within a culture and which enhance the legitimacy of a given institution (Mackay, Monro and Waylen 2009). Borrowing from these SI main tenets, feminist institutionalists have unveiled the gender dimensions of the 'logic of appropriateness' and its role in resistances to institutional change. More specifically, they have shown how the 'logic of appropriateness' is presented in a gender-neutral disguise and how, the more embedded and enforced this norm of gender neutrality is, the harder it is for feminists to advance claims of gender bias (Chappell 2006). This finding resonates with the deep entrenchment of the norm of neutrality of the merit principle and can help explain how hard it is for feminists to contest it and subvert it. By focusing on the role of culture, SI analyses of gender and institutions can be quite useful for explaining institutional similarities (for example, isomorphisms in institutional norms, procedures and practices in universities across different countries). Nonetheless, it cannot adequately explain differences resulting from institutional change, particularly endogenous institutional change (Mackay, Monro and Waylen 2009).

Historical institutionalism focuses on the evolution of institutions over time and aims to unveil the causal mechanisms underlying institutions' historical development. This is carried out through methods of comparative research and historical process-tracing (Waylen 2009: 246). In this analytical framework, once an institution is created, it tends towards a 'path dependency', embedding a set of both formal and informal rules that constrain future opportunities for institutional change (Pierson, 2004). The notion of 'path dependence' does not imply that institutions are historically determined (Kenny 2007: 93), but rather that these path-dependency processes provide the conditions that render a certain course of action more or less appropriate than others (Kulawik 2009: 265).

Feminist institutionalists have found HI very valuable for understanding the role played by historical factors in resistance to institutional change towards gender equality. As gender norms become entrenched in the structures and practices of an institution over time, they shape what is considered 'normal' or 'common sense', and therefore these norms become invisible (Kronsell 2016). The notion of 'path dependence' is useful for addressing questions concerned with the role of institutional legacies in resisting change towards gender equality in higher education. It helps to understand the deep entrenchment of the neutrality of the merit principle and why it is so difficult to contest and subvert this norm. It also helps to explain why a change in the formal institutional rules of an organisation (for example, a rule dictating that selection panels in academic recruitment and promotion should be gender balanced) is not sufficient to tackle gender bias in decision-making processes.

HI can also illuminate comparative analyses of varying outcomes of gender practices, not only in different academic institutions but also in different academic fields. As we have seen in the previous section, academic institutions are not monolithic entities, and one of the explanations for this is that they are historically constituted. Historical institutionalism can help illuminate how the merit principle became a core institutional rule (both formal and informal) in academic practices and procedures; how this is being interpreted in different universities and academic fields and why it produces varying gendered outcomes.

Another advantage of HI is its attention to power. As Hall and Taylor contend (1996: 941), HI is more likely than other variants to assume a world in which institutions have historically privileged some groups over others, giving them more access to decision-making processes, and more rewards and recognition from the institution.

However, this variant of new institutionalism has limitations. One such limitation is a strong focus on causal factors, which can be inadequate for studies examining resistances to change in academic institutions that aim to go beyond an understanding of its causes. Put differently, 
the question of how the merit principle is created, re-created, reinforced, contested and/or subverted through institutional (gendered) practices goes beyond the historical, pathdependence, legacy explanation offered through $\mathrm{HI}$.

Discursive institutionalism (DI), the most recent variant of new institutionalism, can overcome some limitations of HI. Focusing on ideas and on the interactive processes of discourse through which these ideas are generated and communicated, this approach views institutions and their rules as 'simultaneously constraining structures and enabling constructs of meaning which are internal to strategic actors seeking to realize complex and contingent goals (Schmidt 2010: 4).

DI has been particularly amenable to feminist appropriation and it is thus the preferred variant of many scholars investigating the interplay between gender, institutions and institutional continuity and change. On the one hand, DI highlights the importance of discourse and its relationship to power in generating and legitimising ideas and cementing the gendered 'status quo' of an institution. Dominant ideas become so accepted that their very existence may be forgotten, yet they structure people's taken-for-granted views (such as those in relation to the merit principle) as well as the methods, instruments and goals used (for example, in merit assessments). However, DI also highlights the role of agency, as it focuses on the interactive processes by which ideas are generated, communicated, deliberated, and/or contested. In doing so, it acknowledges the existence of discursive struggles and can show how the 'status quo' is capable of change (Fischer 2003).

One problem with DI is that it erases the distinction between institutions and discourses (Freidenvall and Krook 2007). Once this distinction is blurred, it is hard to identify the conditions under which actors 'use' discourse to effect institutional change (that is, a change in the formal/informal rules of the organisation) or the moments when actors are being 'used' by discourse in resisting such change.

Kulawik (2009) shows how historical and discursive variations of new institutionalism complement each other and how they can be used in an integrated (feminist) approach by deconstructing the dichotomy of causal explanation versus meaning and description, and reformulating (rather than eschewing) the concept of causality. In their view, an adequate explanation must include the concept of meaning. In conducting comparative analyses, it is important to take into account that countries differ not only in terms of their institutions 'but also in the way that problems and their causes are interpreted, which, in turn, influence the solutions that are deemed appropriate' (Kulawik 2009: 266).

At this point in the evolution of feminist institutionalist theory, an integrated approach that borrows from the strengths of both HI and DI can be particularly useful for an analysis of institutional change towards gender equality and the resistances to such changes in academic settings. This facilitates discourse analyses of how gendered institutional rules such as the merit principle is interpreted, who holds the power and legitimacy over these interpretations and how change can come about through discursive contestations. At the same time, the HI concept of 'path dependence' can illuminate a meso-level analysis of differences among and within higher education institutions with regards to varying interpretations of institutional rules such as the merit principle. HI also allows for an analysis of the wider institutional context in which change occurs, looking for critical junctures and opening up the possibility that change may be unforeseen at the time, or be the outcome of unintended consequences.

\section{Conclusions}

This article has explored research on gender and institutions for the purposes of informing analytical frameworks for research on institutional change in higher education contexts. Drawing on the feminist institutionalist literature that explores the relationship between 
gender, institutions and institutional continuity and change, the aim was to evaluate how this body of work, together with contributions from gender and organisational studies, could be adapted to a study seeking to understand the dynamics of implementation of gender equality action plans (GEPs) in higher education institutions around Europe.

While GEPs in universities are becoming the norm and there is evidence of some progress towards gender equality in this sector, legislative and policy efforts are not sufficiently translated into desired outcomes. In understanding the factors hindering implementation, this article turned to the concept of resistances to institutional change. This concept has been unpacked by gender scholars working with new institutionalist frameworks with the aim of gaining a better grasp of cases of failure (or partial success) in the implementation of gender equality initiatives in the political realm. Their work uncovers the role of informal (gendered) institutional rules in hindering change towards gender equality and also highlights their informal and implicit nature. In the light of this insight, this article discussed the difficulties involved in the construction of appropriate methodologies for the identification, analysis and evaluation of resistances in the context of empirical research.

However, while the gender and politics literature inspired by new institutionalist frameworks can provide useful conceptual and methodological tools for constructing a research design focused on academic institutions, an isomorphism with political institutions cannot be assumed. For this reason, this study turned to research, mostly inspired by gender and organisational studies, which examines resistances to institutional change towards gender equality in the specific setting of academia. Among the many factors hindering gender equality initiatives and practices in universities, that research highlights the role of academic merit as a major obstacle. Disguised as a gender neutral and objective norm, it constrains transformative change not only in implementation processes but also in earlier processes of policy formulation and adoption.

There are different feminist institutionalist approaches (each drawing on the different variants of new institutionalist theory) that can be used to inform a research design aimed at a better understanding of the merit principle as a major source of resistance constraining the design and implementation of GEPs. This article ends with a discussion of the merits and weaknesses of these approaches for a study focussed on academic institutions, concluding that an integrated approach borrowing from more than one variant has two advantages. First, it provides the flexibility needed for a study where there is little research available to date, and second, it can remedy the shortcomings associated with the rigid adoption of just one individual approach. At any rate, the choice of approach ultimately depends on the specific research questions, objectives and methodologies of the study.

\section{References}

Acker, J. (1990) 'Hierarchies, jobs, bodies: a theory of gendered organizations', Gender \& Society 4 (2): 139-58

Acker, J. (1992) 'From sex roles to gendered institutions', Contemporary Sociology 21 (5): 565-569.

Annesley, C. and Gains, F. (2010) 'The core Executive: gender, power and change', Political Studies 58 (5): 909-929.

Benschop, Y. and Doorewaard, H. (2012) 'Gender subtext revisited' Equality, Diversity, and Inclusion: an International Journal, 31 (3): 225-235 
Bergqvist, C., Bjarnegård, E., and Zetterberg, P. (2013) 'Analysing failure, understanding success: a research strategy for explaining gender equality policy adoption', NORA - Nordic Journal of Feminist and Gender Research 21(4): 280-295.

Chappell, L. (2006) 'Comparing political institutions: revealing the gendered logic of appropriateness', Politics \& Gender 2(2): 223-235

Chappell (2011) 'Nested newness and institutional innovation: expanding gender justice in the International Criminal Court', in M.L Krook \& F. Mackay (eds) Gender, Politics and Institutions: Towards a Feminist Institutionalism, Palgrave Macmillan, pp. 163-180

Chappell, L. and Waylen, G (2013) 'Gender and the hidden life of institutions', Public Administration 91(3): 599-615

Connell (1987) Gender and Power: Society, the Person and Sexual Politics. Cambridge: Polity Press.

Connell, R.W. (2002) Gender. Cambridge: Polity Press.

Council of the European Union (2015) Advancing gender equality in the European Research Area: Council Conclusions, 14846/15, http://data.consilium.europa.eu/doc/document/ST$\underline{14846-2015-I N I T / e n / p d f}$

Driscoll, A. and Krook, L. (2009) 'Can there be a feminist rational choice institutionalism?', Politics \& Gender 5(2): 238-245.

Driscoll, A. and Krook, L. (2012) 'Feminism and rational choice theory', European Political Science Review 4(2): 195-216.

EIGE (2016) Gender Equality in academia and research - GEAR tool. https://eige.europa.eu/gender-mainstreaming/toolkits/gear

Erickson, S. K. (2012) 'Women Ph.D. students in engineering and a nuanced terrain: Avoiding and revealing gender' The Review of Higher Education, 35(3): 355-374

Erikson-Zetterquist, U. and Renemark, D. (2016) 'Can changes to gender equality be sustained?' Gender, Work \& Organization 23 (4): 363-378

European Commission (2004) Gender and Excellence in the Making. https://www.unifrankfurt.de/41563255/GenderMainstreaming.pdf

European Commission (2005) The European Charter for Researchers and The Code of Conduct for the Recruitment of Researchers.

https://euraxess.ec.europa.eu/sites/default/files/am509774cee en e4.pdf

European Commission (2016) SHE figures 2015.

https://ec.europa.eu/research/swafs/pdf/pub_gender equality/she figures 2015-final.pdf

European Commission (2018) Report on equality between women and men in the EU. https://publications. europa.eu/en/publication-detail/-/publication/950dce57-6222-11e8-ab9c01aa75ed71a1/language-en

European Commission (2019a) ERA progress report 2018. Data gathering and information for the 2018 ERA monitoring - Technical Report.

https://ec.europa.eu/info/sites/info/files/research and innovation/era/era progress report 20 18-technical.pdf

European Commission (2019b) SHE figures 2018. https://ec.europa.eu/info/publications/shefigures-2018 en 
Fischer, F. (2003) Reframing Public Policy: Discursive Politics and Deliberative Practices. Oxford: Oxford University Press.

Fox, M. F. (2008) 'Institutional transformation in the advancement of women faculty: The case of academic science and engineering. In J.C. Smart (ed) Higher Education: Handbook of Theory and Research, New York: Springer (pp. 73-103)

Gains, F. and Lowndes, V. (2014) 'How does the gendered organisation of political life make a difference? Examining an institution in formation - Police and Crime Commissioners in England and Wales', Politics and Gender 1 (4): 524-548

Hall, P.A. and Taylor, R.C.R. (1996) 'Political science and the three new institutionalisms', Political Studies 44 (5): 936-957.

Hart, J. (2008) 'Mobilization among women academics: The interplay between feminism and professionalization' National Women's Studies Association (NWSA) Journal, 20 (1): 184208.

Hart, J. (2016) 'Dissecting a gendered organization: Implications for career trajectories for mid-career women in STEM' Journal of Higher Education, 87: (5), 605-634.

Kanter, R.M. (1977) 'Some effects of proportions on group life: skewed sex ratios and responses to token women', American Journal of Sociology 82 (5): 965-990

Kantola, J. (2006) Feminists Theorize the State. Basingstoke: Palgrave Macmillan

Kenney, S.J (1996) 'New research on gendered political institutions' Political Research Quarterly 49(2): 445-466.

Kenny, M. (2007) 'Gender, Institutions and Power: A Critical Review', Politics 27(2): 19100

Kezar, A. and Eckel, P. (2002) 'The effect of institutional culture on change strategies in higher education: Universal principles or culturally responsive concepts?' The Journal of Higher Education, 73(4): 435-460.

Kezar, A., \& Lester, J. (2011) Enhancing campus capacity for leadership: An examination of grassroots leaders in higher education, Stanford, CA: Stanford University Press.

Kezar, A. (2014) Higher education change and social networks: a review of research' The Journal of Higher Education 85 (1): 91-124.

Kronsell, A. (2016) 'Sexed bodies and military masculinities : gender path dependence in EU's Common Security and Defense Policy, Men and Masculinities, 19 (3): 311-336.

Krook, M.L. and Mackay, F. (eds.) (2011) Gender, Politics and Institutions: Towards a Feminist Institutionalism. Basingstoke: Palgrave Macmillan.

Kulawik, T. (2009) 'Staking the frame of a feminist discursive institutionalism', Politics \& Gender 5(2): 261-271

LERU (2012) Women. Research and Universities. Excellence without Gender Bias. http://www.leru.org/files/publications/LERU_Paper_Women_universities and research.pdf

Lester, J. (2008) 'Performing gender in the workplace: Gender socialization, power, and identity among women faculty members' Community College Review, 35 (4): 277-305

Lester, J., Sallee, M. and Hart, J. (2017) 'Beyond Gendered Universities? Implications for Research on Gender in Organizations' NASPA Journal About Women in Higher Education, 10 (1): $1-26$. 
Lombardo, E. and Mergaert, L. (2013) 'Gender mainstreaming and resistance to gender training: a framework for studying implementation', NORA - Nordic Journal of Feminist and Gender Research, 21(4): 296-311.

Lovenduski, J. (2008)' State feminism and women's movements' West European Politics 31(1/2): 169-194.

Mackay, F., Kenny, M. and Chappell, L. (2010) 'New institutionalism through a gender lens: towards a feminist institutionalism?' International Political Science Review 31(5): 573-588.

Mackay, F., Monro, S. and Waylen, G. (2009) 'The feminist potential of sociological institutionalism' Politics \& Gender 5(2): 253-262.

Mackay, F. and Waylen, G. (2009) 'Feminist institutionalism' Politics \& Gender 5(2): 237280 .

McBride, D.E. and Mazur, A.G. (eds) (2010) The Politics of State Feminism: Innovation in Comparative Research. Philadelphia: Temple University Press.

Mergaert, L. and Lombardo, E. (2014) 'Resistance to Implementing Gender Mainstreaming in EU Research Policy', in E. Weiner and H. MacRae (eds.) 'The Persistent Invisibility of Gender in EU Policy' European Integration Online Papers (EIoP), Special issue 1(18), Article 5, http://eiop.or.at/eiop/texte/2014-005a.htm, 121.

Olsen J. (2009) 'Change and continuity: an institutional approach to institutions of democratic government' European Political Science Review, 1(1): 3-32.

O’Meara, K. and Stromquist, N. (2015) 'Faculty Peer Networks: Role and Relevance in Advancing Agency and Gender Equity' Gender and Education 27(3), 338-358

Outshoorn, J. and Kantola. J. (2007) Changing State Feminism. Basingstoke: Palgrave Macmillan.

Penney, S..; Brown, J.; and Oliveria, L. (2007) 'Numbers are not enough: women in higher education in the 21st century' New England Journal of Public Policy, 22 (1) Article 14. http://scholarworks.umb.edu/nejpp/vol22/iss1/14

Pierson, P. (2004) Politics in Time: History, Institutions and Social Analysis. Princeton: Princeton University Press.

Sallee, M. W. (2012) 'The ideal worker or the ideal father: Organizational structures and culture in the gendered university' Research in Higher Education, 53(7): 782-802.

Schmidt, V. (2010) 'Taking ideas and discourse seriously: explaining change through discursive institutionalism as the fourth 'new institutionalism' European Political Science Review 2(1): 1-25

The authors (2018) 'Do Gender Equality Plans aid in building epistemic justice in Higher Education? Evidence from six European universities' Paper presented at the International Political Science Association World Congress, Brisbane, Australia, 22-25 July 2018, Panel AUS 04.04 Contemporary Public Policy Challenges.

https://www.researchgate.net/publication/326395871 Do Gender Equality Plans aid in bu ilding epistemic justice in Higher Education Evidence from six European universities

Thomas, L., Hill, M., O’Mahony, J. and Yorke, M. (2017) Supporting student success: strategies for institutional change. Advance HE. https://www.advance-he.ac.uk/knowledgehub/supporting-student-success-strategies-institutional-change

Thornton,M. (2013) 'The mirage of merit' Australian Feminist Studies, 28(76): 127-143 
Van den Brink, M. and Benschop, Y. (2012) 'Slaying the seven-headed dragon: the quest for gender change in academia' Gender, Work \& Organization 19(1): 71-92.

Ward, K. and Wolf-Wendel, L (2012) Academic motherhood: How faculty manage work and family. Rutgers University Press.

Waylen, G. (2009) 'What can historical institutionalism offer feminist institutionalists?

Politics \& Gender 5(2): 245-253

Waylen (2014) Informal Institutions, Institutional Change and Gender Equality', Political Research Quarterly, 67(1): 212-223. 